\title{
Does the Mean Arterial Pressure Influence Mortality Rate in Patients with Acute Hypoxemic Respiratory Failure under Mechanical Ventilation?
}

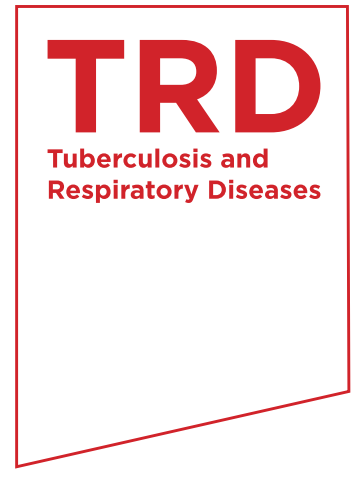

\author{
Juarda Gjonbrataj, M.D. ${ }^{1,2}$, Hyun Jung Kim, M.D. ${ }^{1 *}$, Hye In Jung, M.D. ${ }^{1}$ and Won-Il Choi, M.D., Ph.D. ${ }^{1}$ \\ ${ }^{1}$ Department of Internal Medicine, Keimyung University School of Medicine, Daegu, Korea, ${ }^{2}$ Department of Internal Medicine,
} Mother Thereza University Hospital, Tirana, Albania

Background: In sepsis patients, target mean arterial pressures (MAPs) greater than $65 \mathrm{~mm} \mathrm{Hg}$ are recommended. However, there is no such recommendation for patients receiving mechanical ventilation. We aimed to evaluate the influence of MAP over the first 24 hours after intensive care unit (ICU) admission on the mortality rate at 60 days postadmission in patients showing acute hypoxemic respiratory failure under mechanical ventilation.

Methods: This prospective, multicenter study included 22 ICUs and compared the mortality and clinical outcomes in patients showing acute hypoxemic respiratory failure with high (75-90 $\mathrm{mm} \mathrm{Hg}$ ) and low (65-74.9 $\mathrm{mm} \mathrm{Hg}$ ) MAPs over the first 24 hours of admission to the ICU.

Results: Of the 844 patients with acute hypoxemic respiratory failure, 338 had a sustained MAP of 65-90 mm Hg over the first 24 hours of admission to the ICU. At 60 days, the mortality rates in the low (26.2\%) and high (24.5\%) MAP groups were not significantly different. The ICU days, hospital days, and 60-day mortality rate did not differ between the groups. Conclusion: In the first 24 hours of ICU admission, MAP range between 65 and $90 \mathrm{~mm} \mathrm{Hg}$ in patients with acute hypoxemic respiratory failure under mechanical ventilation may not cause significantly differences in 60-day mortality.

Keywords: Arterial Pressure; Respiratory Insufficiency; Respiration, Artificial

\section{Introduction}

Address for correspondence: Won-II Choi, M.D., Ph.D.

Department of Internal Medicine, Keimyung University School of

Medicine, 56 Dalseong-ro, Jung-gu, Daegu 700-712, Korea

Phone: 82-53-250-7572, Fax: 82-53-250-8379

E-mail:wichoi@dsmc.or.kr

Received: Sep. 11, 2014

Revised: Oct. 7, 2014

Accepted: Dec. 10, 2014

* Juarda Gjonbrataj and Hyun Jung Kim contributed equally to this work.

(a) It is identical to the Creative Commons Attribution Non-Commercial License (http://creativecommons.org/licenses/by-nc/3.0/).

Copyright $\odot 2015$

The Korean Academy of Tuberculosis and Respiratory Diseases.

All rights reserved.
Acute hypoxemic respiratory failure (AHRF) is a common disease in the intensive care unit (ICU), and frequently requires mechanical ventilation. The condition may be caused by left ventricular failure, increased alveolar capillary permeability as observed in acute respiratory distress syndrome (ARDS), diffuse alveolar haemorrhage, or inflammatory exudates such as those observed in pneumonia or other inflammatory lung conditions ${ }^{1}$. AHRF in mechanically ventilated patients can present in an ARDS or non-ARDS form. Acute respiratory failure occurs in $56 \%$ of all patients in the ICU and the mortality rate is $34 \%^{2}$. In other cohort studies, the mortality rates in AHRF patients were found to be higher than $40 \%^{3,4}$.

The role of arterial blood pressure on outcomes and mortality is well studied in shock patients ${ }^{5,6}$. However, there is paucity of data about the role of mean arterial pressure (MAP) in AHRF patients under mechanical ventilation. One study 
found that impaired perfusion of small vessels caused alterations in microcirculation and had an important effect on outcomes and survival in patients with septic shock ${ }^{7}$. Additional studies conducted on patients with septic shock found that increases in MAP from $65 \mathrm{~mm} \mathrm{Hg}$ to $85 \mathrm{~mm} \mathrm{Hg}$ were not related to tissue perfusion or mortality ${ }^{8,9}$. However, both the effect of MAP on mortality rate and the maintenance of a blood pressure target in shock patients remain controversial.

Mechanical ventilation is critical for the survival of most ICU patients with AHRF. However, over-inflation of the lung, which frequently occurs with mechanical ventilation, raises the stresses in the capillary walls to high levels. This leads to ultrastructural changes in the barrier, a condition known as stress failure $^{10}$. As a result, mechanical ventilation itself may cause additional lung injury, affecting survival in ICU patients ${ }^{11-13}$.

The Surviving Sepsis Campaign has suggested maintaining a target MAP higher than $65 \mathrm{~mm} \mathrm{Hg}$ in cases of septic shock ${ }^{14}$. However, there is no such recommendation for mechanically ventilated patients. We hypothesized that MAP may influence survival in mechanically ventilated patients with AHRF. We divided mechanically ventilated patients with AHRF into two groups depending on their MAP over the first 24 hours after ICU admission: the first low MAP group consisted of individuals with MAP ranging from 65 to $74.9 \mathrm{~mm} \mathrm{Hg}$ and the second high MAP group consisted of individuals with MAP from 75 to $90 \mathrm{~mm} \mathrm{Hg}$.

\section{Materials and Methods}

\section{Subjects and study design}

This study is a subgroup analysis of a prospective cohort study that consisted of patients from 22 ICUs in Korea, and data from the "Validation of Simplified Acute Physiology Score 3 in Korean ICUs (VSKI)" study. Participating hospital units were enrolled voluntarily. The VSKI study included 22 ICUs ( 14 medical, 6 surgical, and 2 multidisciplinary) in 15 tertiary-level hospitals. Approval from the respective ethics committees was obtained at each hospital. All adult patients with AHRF admitted to the participating ICUs were screened regardless of ARDS status starting on July 1, 2010, through to January 31,2011 . The patients with a $\mathrm{PaO}_{2} / \mathrm{FIO}_{2}$ ratio less than $300 \mathrm{~mm} \mathrm{Hg}$ at ICU admission during the study period formed the study cohort. The patients were classified into two groups according to MAP over the first 24 hours: the low MAP group (65-74.9 $\mathrm{mm} \mathrm{Hg}$ ) and the high MAP group (75-90 $\mathrm{mm} \mathrm{Hg}$ ).

\section{Data collection}

Demographic information including age, gender, MAP, body mass index, co-morbid conditions, acute lung injury (ALI) risk factors, vital signs, and laboratory features were recorded. The disease severity was assessed based on the Simplified Acute Physiology Score III (SAPS III) ${ }^{15}$ and the Sequential Organ Failure Assessment (SOFA) score ${ }^{16}$ at ICU admission. The duration of hospitalization and duration in the ICU was also measured for each patient. Patients were followed up for 60 days following hospital admission.

\section{Outcomes}

The primary outcome of this study was the 60-day mortality rate for AHRF with high (75-90 mm Hg) and low (65-74.9 $\mathrm{mm} \mathrm{Hg}$ ) MAP over the first 24 hours of ICU admission. Secondary outcomes included the durations of hospital and ICU stay in both groups.

\section{Statistical analysis}

Data were presented as mean (standard deviation) for continuous variables and the number of subjects (\%) for categorical variables. Categorical variables were compared using the Fisher exact test or Pearson $\chi^{2}$ test as appropriate, and continuous variables were compared by the Mann-Whitney $\mathrm{U}$ test or Student $\mathrm{t}$ test, after determining normality using the Kolmogorov-Smirnov test. All tests for significance were twotailed, and a p-value of less than 0.5 was considered significant. Multivariate linear (for continuous variables) and logistic (for categorical variables) regressions were used to evaluate the association between MAP in the first 24 hours of admission and survival. Survival curves for both study groups were compared using the log-rank test. Results were analyzed with SPSS version 20.0 for Windows (SPSS Inc., Chicago, IL, USA).

\section{Results}

Of the 844 patients diagnosed with AHRF, 338 individuals fulfilled the required criteria for our study (Figure 1). The population demographics for patients with low MAP over the first 24 hours as compared to the patients with high MAP over the first 24 hours is summarized in Table 1 . The mean patient age in both groups was 60 years, and $65 \%$ of all patients were men. Sepsis was the most probable cause of AHRF in $26 \%$ of patients, while cancer and diabetes were the most common co-morbidities, affecting 89 (26\%) and 79 (23\%) patients, respectively. Chronic obstructive pulmonary disease as a co-morbidity occurred in a significantly higher number of patients with high MAP than in patients with low MAP. Meanwhile sepsis affected higher percentage of patients with low MAP than those with high MAP. The high MAP group had a significantly higher $\mathrm{PaO}_{2} / \mathrm{FIO}_{2}$ ratio and C-reactive protein than the low MAP group. ARDS was present in $20 \%$ of the patients with low MAP, and in $22.4 \%$ of the patients with high MAP. The duration of ICU stay, hospital stay, and 60-day mor- 


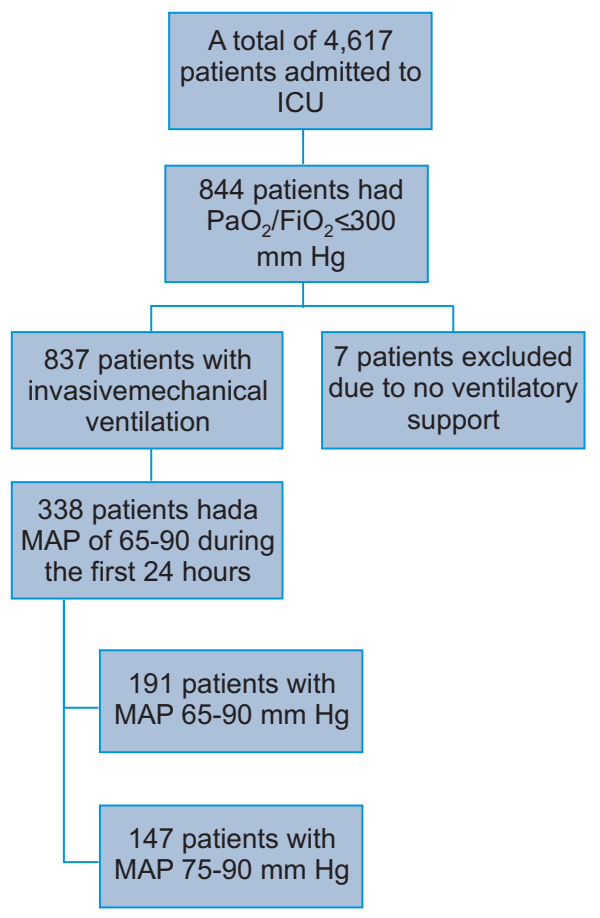

Figure 1. Flow chart of patients who sustained mean arterial pressure (MAP) of 65 to $90 \mathrm{~mm} \mathrm{Hg}$ over the first 24 hours of the intensive care unit (ICU) admission among hypoxemic respiratory failure. tality rate did not differ between the two groups.

A multivariate analysis was performed to evaluate the independent factors affecting the 60-day mortality rate in mechanically ventilated AHRF patients. The MAP in the first 24 hours is not an independent factor associated with 60-day mortality rate. We found that the SAPS III score and the $\mathrm{PaO}_{2} / \mathrm{FiO}_{2}$ ratio

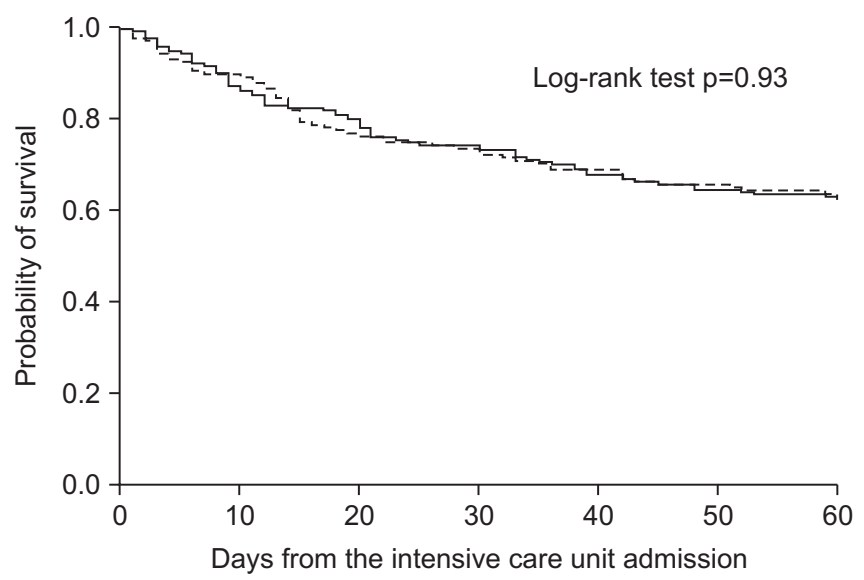

Figure 2. Kaplan-Meier survival curves: patients with low mean arterial pressure (MAP) (65-74.9 $\mathrm{mm} \mathrm{Hg}$ ) (solid line) compared to patients with high MAP (75-89.9 $\mathrm{mm} \mathrm{Hg}$ ) (dotted line).

Table 1. Patient demographics, risk factors, co-morbidities, and clinical outcomes of 338 AHRF patients admitted to the ICU

\begin{tabular}{|c|c|c|c|}
\hline Characteristic & $\begin{array}{c}\text { Low MAP } \\
(65-74.9 \mathrm{~mm} \mathrm{Hg})(\mathrm{n}=191)\end{array}$ & $\begin{array}{c}\text { High MAP } \\
(75-90 \mathrm{~mm} \mathrm{Hg})(\mathrm{n}=147)\end{array}$ & p-value \\
\hline MAP at admission & $80.2 \pm 15.1$ & $90.9 \pm 18.9$ & $<0.001$ \\
\hline MAP at first $24 \mathrm{hr}$ & $69.6 \pm 2.9$ & $80.4 \pm 4.2$ & $<0.001$ \\
\hline Age, yr & $63.3 \pm 15.4$ & $62.4 \pm 14.6$ & 0.59 \\
\hline Sex (male) & $131(68.6)$ & $89(60.5)$ & 0.09 \\
\hline BMI & $22.3 \pm 4.2$ & $22.8 \pm 4.2$ & 0.32 \\
\hline \multicolumn{4}{|l|}{ Co-morbidity } \\
\hline Hepatic cirrhosis & $16(8.4)$ & $13(8.8)$ & 0.88 \\
\hline Ischemic heart disease & $10(5.2)$ & $12(8.2)$ & 0.28 \\
\hline Stroke & $12(6.3)$ & $12(8.2)$ & 0.51 \\
\hline COPD & $11(5.7)$ & $17(11.6)$ & 0.05 \\
\hline Diabetes mellitus & $46(24.1)$ & $33(22.4)$ & 0.73 \\
\hline Chronic renal failure & $15(7.8)$ & $13(8.8)$ & 0.74 \\
\hline Cancer & $47(24.6)$ & $42(28.6)$ & 0.41 \\
\hline Congestive heart failure & $7(3.7)$ & $6(4.1)$ & 0.84 \\
\hline Alcoholics & $5(2.6)$ & $3(2)$ & 0.73 \\
\hline ARDS & $38(20)$ & $33(22.4)$ & 0.56 \\
\hline \multicolumn{4}{|l|}{ Risk factors } \\
\hline Aspiration & $12(6.3)$ & $14(9.5)$ & 0.27 \\
\hline Pneumonia & $28(14.7)$ & $19(12.9)$ & 0.79 \\
\hline
\end{tabular}


Table 1. Continued

\begin{tabular}{|c|c|c|c|}
\hline Characteristic & $\begin{array}{c}\text { Low MAP } \\
(65-74.9 \mathrm{~mm} \mathrm{Hg})(n=191)\end{array}$ & $\begin{array}{c}\text { High MAP } \\
(75-90 \mathrm{~mm} \mathrm{Hg})(\mathrm{n}=147)\end{array}$ & p-value \\
\hline Sepsis & $61(31.9)$ & $29(19.7)$ & 0.01 \\
\hline Orthopaedic surgery & $1(0.5)$ & $2(1.4)$ & 0.42 \\
\hline Acute abdomen & $23(12)$ & $16(10.9)$ & 0.74 \\
\hline Cardiac surgery & $1(0.5)$ & $1(0.7)$ & 0.85 \\
\hline Aortic reconstruction & $0(0)$ & $1(0.7)$ & 0.25 \\
\hline Chemotherapy & $20(10.5)$ & $17(11.6)$ & 0.75 \\
\hline HIV & $0(0)$ & $1(0.7)$ & 0.25 \\
\hline Leukocytes & $12,272 \pm 8,181$ & $12,259 \pm 7,490$ & 0.99 \\
\hline \multicolumn{4}{|l|}{ Illness severity at ICU admission } \\
\hline SAPS III score & $67.8 \pm 14.1$ & $61.6 \pm 14.2$ & 0.001 \\
\hline SOFA & $11.2 \pm 9.1$ & $12 \pm 12.8$ & 0.50 \\
\hline \multicolumn{4}{|l|}{ At ICU admission } \\
\hline Temperature & $36.6 \pm 0.9$ & $36.5 \pm 0.8$ & 0.64 \\
\hline Heart rate & $94.5 \pm 24.3$ & $97.3 \pm 23.3$ & 0.29 \\
\hline Platelets & $193,656 \pm 125,903$ & $190,810 \pm 122,350$ & 0.83 \\
\hline Creatinine & $1.6 \pm 2$ & $1.5 \pm 1.7$ & 0.46 \\
\hline Sodium & $137.2 \pm 6.5$ & $137.9 \pm 6$ & 0.31 \\
\hline $\mathrm{PaO}_{2} / \mathrm{FiO}_{2}$ ratio & $161.5 \pm 69$ & $176.9 \pm 74.3$ & 0.04 \\
\hline Fluid intake over the first $24 \mathrm{hr}, \mathrm{mL}$ & $3,765.0$ & $3,584.1$ & 0.64 \\
\hline Urine output in first $24 \mathrm{hr}, \mathrm{mL}$ & $1,928.6$ & $1,796.9$ & 0.43 \\
\hline Highest PEEP at $24 \mathrm{hr}$ & $6.6 \pm 4.2$ & $6.3 \pm 4.9$ & 0.57 \\
\hline CRP & $136.9 \pm 516.8$ & $425.7 \pm 1198.4$ & 0.01 \\
\hline Potassium & $4.2 \pm 1$ & $4 \pm 0.9$ & 0.10 \\
\hline \multicolumn{4}{|l|}{ Outcomes } \\
\hline Duration in ICU, day & $11.5 \pm 12.3$ & $16.6 \pm 41.1$ & 0.18 \\
\hline Duration in hospital, day & $25.8 \pm 30.5$ & $25.5 \pm 27.2$ & 0.92 \\
\hline 60-Day mortality rate & $50(26.2)$ & $36(24.5)$ & 0.95 \\
\hline
\end{tabular}

Values are presented as mean \pm standard deviation or number (\%).

AHRF: acute hypoxemic respiratory failure; ICU: intensive care unit; MAP: mean arterial pressure; BMI: body mass index; COPD: chronic obstructive pulmonary disease; ARDS: acute respiratory distress syndrome; HIV: human immunodeficiency virus; SAPS III: Simplified Acute Physiology Score III; SOFA: Sequential Organ Failure Assessment; $\mathrm{PaO}_{2}$ : partial pressure of oxygen; FiO ${ }_{2}$ : fraction of inspired oxygen; PEEP: positive end-expiratory pressure; CRP: C-reactive protein.

are independently associated with 60-day mortality rate (Table 2).

The Kaplan-Meier survival curves demonstrated the same survival rates for patients with high and low MAP over the first 24 hours of admission to the ICU. The 60-day mortality rate was approximately $60 \%$ for both study groups (Figure 2).

To ensure that the MAP was maintained in excess of 65 mm Hg in our study patients, we used fluid perfusions and vasopressors. The number of patients receiving vasopressors in the low MAP group was significantly higher than in the high
MAP group. The mean dosage for each vasopressor used did not differ between the two groups. Norepinephrine alone or combined with dopamine was used in most patients (Table 3).

\section{Discussion}

To clarify the relationship between MAP observed over the first 24 hours of admission and the 60-day mortality rate, and ICU outcomes in patients with AHRF, we performed a sub- 
Table 2. Multivariate analysis for 60-day mortality rate as the dependent variable

\begin{tabular}{|lccccc|}
\hline \multicolumn{1}{|c}{ Variable } & Coefficient & SE & p-value & OR & 95\% CI \\
\hline 24-hr MAP & -0.004 & 0.024 & 0.88 & 0.99 & $0.95-1.04$ \\
Sex (male) & -0.44 & 0.33 & 0.89 & 0.95 & $0.50-1.83$ \\
COPD & 0.55 & 0.59 & 0.35 & 1.73 & $0.53-5.59$ \\
Sepsis & 0.21 & 0.35 & 0.58 & 1.23 & $0.62-2.43$ \\
SAPS III score & 0.06 & 0.015 & $<0.001$ & 0.06 & $1.03-1.09$ \\
$\mathrm{CRP}$ & -0.001 & -1.14 & 0.25 & 0.99 & $0.99-1.00$ \\
$\mathrm{PaO}_{2} /$ FiO $_{2}$ ratio & -0.005 & 0.002 & 0.03 & 0.99 & $1.00-1.00$ \\
Vasopressors infusion & 0.18 & 0.32 & 0.57 & 1.19 & $0.63-2.27$ \\
\hline
\end{tabular}

SE: standard error; OR: odds ratio; CI: confidence interval; MAP: mean arterial pressure; COPD: chronic obstructive pulmonary disease; SAPS III: Simplified Acute Physiology Score III; CRP: C-reactive protein; $\mathrm{PaO}_{2}$ : partial pressure of $\mathrm{O}_{2}$; $\mathrm{FiO}_{2}$ : fraction of inspired oxygen.

Table 3. A univariate analysis of the effect of vasopressor administration in patients with AHRF under mechanical ventilation

\begin{tabular}{|c|c|c|c|c|c|}
\hline \multirow[t]{2}{*}{ Variable } & \multicolumn{2}{|c|}{$\begin{array}{c}\text { Low MAP } \\
(65-74.9 \mathrm{~mm} \mathrm{Hg}) \\
(\mathrm{n}=191)\end{array}$} & \multicolumn{2}{|c|}{$\begin{array}{c}\text { High MAP } \\
(75-90 \mathrm{~mm} \text { Hg }) \\
(\mathrm{n}=147)\end{array}$} & \multirow[t]{2}{*}{ p-value } \\
\hline & No. (\%) & Mean \pm SD & No. & Mean \pm SD & \\
\hline Vasopressor & $96(50.3)$ & & $47(32)$ & & 0.02 \\
\hline Dopamine 24 hr, $\mu \mathrm{g} / \mathrm{kg} / \mathrm{min}$ & 28 & $10.6 \pm 8.9$ & 25 & $8.1 \pm 9.5$ & 0.33 \\
\hline Norepinephrine 24 hr, $\mu \mathrm{g} / \mathrm{kg} / \mathrm{min}$ & 71 & $1.3 \pm 3.4$ & 32 & $2.4 \pm 5.3$ & 0.23 \\
\hline Vasopressin $24 \mathrm{hr}$, unit/min & 10 & $0.012 \pm 0.016$ & 8 & $0.008 \pm 0.011$ & 0.56 \\
\hline Epinephrine $24 \mathrm{hr}, \mu \mathrm{g} / \mathrm{kg} / \mathrm{min}$ & 7 & $0.01 \pm 0.02$ & 5 & $0.00 \pm 0.00$ & 0.22 \\
\hline
\end{tabular}

AHRF: acute hypoxemic respiratory failure; MAP: mean arterial pressure; SD: standard deviation.

group analysis of a prospective, multicenter study in 22 ICUs. We divided the patients that fulfilled our study criteria into two groups according to MAP over the first 24-hour post-admission; a low MAP group (65-74.9 mm Hg), and high MAP group (75-90 $\mathrm{mm} \mathrm{Hg}$ ). We found that there was no difference in 60-day mortality rates between the patients with high and low MAP.

Several other studies have used a range of 65-85 $\mathrm{mm} \mathrm{Hg}$ as an MAP target for the resuscitation of septic shock patients $^{8,9}$. In our study, the MAP over the first 24 hours was $69.6 \mathrm{~mm} \mathrm{Hg}$ and $80.4 \mathrm{~mm} \mathrm{Hg}$ for the low and high MAP groups, respectively. Additionally, in several clinical trials that enrolled patients with ALI or ARDS under mechanical ventilation, the baseline MAP at the time of admission was approximately $76-77 \mathrm{~mm} \mathrm{Hg}$. They aimed to maintain admission MAP over the first 24 hours post-admission ${ }^{17,18}$. However, the optimal arterial blood pressure level in mechanically ventilated AHRF patients is not well known. Therefore, we used an MAP of 65-74.9 mm Hg as a target range, as recommended by the surviving sepsis campaign ${ }^{19}$ and 75-90 $\mathrm{mm} \mathrm{Hg}$ as a high range of MAP.

In a study conducted by Asfar et al..$^{20}$, they showed that the mortality rate of septic shock patients was not related with the MAP. They found the 28-day mortality rate for the high target group (MAP, 80-85 mm Hg) to be $36.6 \%$, and $34.0 \%$ for low target group (MAP, 65-70 mm Hg) ${ }^{20}$. Our study showed that the mortality rates of mechanically ventilated patients did not change in relation to MAP, when maintained above $65 \mathrm{~mm} \mathrm{Hg}$. We found 60-day mortality rates in patients with an MAP of $65-74.9 \mathrm{~mm} \mathrm{Hg}$ to be $26.2 \%$, and $24.5 \%$ in patients with an MAP of $75-90 \mathrm{~mm} \mathrm{Hg}$, with no statistically significant difference between them.

In the present study, the percentage of patients under vasopressor therapy was lower $(42 \%)$ than previous randomized trials on ARDS patents $(73 \%)^{21}$. Furthermore, in the high MAP group in our study, less than $20 \%$ of patients received vasopressor therapy. Multivariate analysis showed vasopressor therapy was not related with 60-day mortality in this study. This finding may help to target blood pressure in mechanically ventilated patients, other than those with underlying sepsis. We used norepinephrine in $37 \%$ of the patients with MAP of $65-74.9 \mathrm{~mm} \mathrm{Hg}$ and in $21 \%$ of the patients with MAP of 75-90 $\mathrm{mm} \mathrm{Hg}$. Norepinephrine was used alone or combined with dopamine. Epinephrine and vasopressin were used in fewer 
patients. The literature reports mean values of norepinephrine perfusion on the first day of admission for septic shock patients ranging from $0.26-0.94 \mu \mathrm{g} / \mathrm{kg} / \mathrm{min}$ in different studies $^{20,22-26}$. In our study, the mean norepinephrine perfusion rate ranged from $1.3-2.4 \mu \mathrm{g} / \mathrm{kg} / \mathrm{min}$, which is higher than previous studies. The highest dose of norepinephrine reported was 3.3 $\mu \mathrm{g} / \mathrm{kg} / \mathrm{min}^{27}$.

We administered almost the same quantity of fluids in both groups of patient. The fluid perfusion dosage in shock patients is previously described as ranging from 1,500-3,500 $\mathrm{mL}^{20,22-26}$. The urine output between patients with MAP of 65$74.5 \mathrm{~mm} \mathrm{Hg}$ and $75-90 \mathrm{~mm} \mathrm{Hg}$ did not differ significantly in the present study. This is in a good agreement with the results of other studies ${ }^{8,9}$. In 2000, LeDoux et al. ${ }^{8}$ found no difference in systemic oxygen metabolism, skin microcirculatory blood flow, urine output, or splanchnic perfusion between patients with MAP ranging between 65-85 mm Hg. In 2009, in a study conducted by Dubin et al. ${ }^{28}$, the increase in arterial blood pressure with norepinephrine did not improve the microcirculatory blood flow.

Despite the fact that sepsis is the most common cause of AHRF, accounting for approximately $26 \%$ of cases and occurring most frequently in the low MAP group, the percentage of sepsis in our study is lower than that observed in other ALI/ ARDS clinical trials ${ }^{21}$. In a French randomized controlled trial, approximately $61 \%$ of the patients had sepsis as a co-morbidi$\mathrm{ty}^{29}$. However, in another clinical trial, only $22 \%$ of the patients were diagnosed with sepsis ${ }^{18}$.

A multivariate analysis showed that SAPS III score and the $\mathrm{PaO}_{2} / \mathrm{FiO}_{2}$ ratio were significantly associated with 60-day mortality rates in patients with AHRF under mechanical ventilation. The duration of the ICU stay, hospital stay, and 60-day mortality rate did not differ between the two groups.

In our study, the 60 -day mortality rate was $26.2 \%$ and $24.5 \%$ for patients with MAP of 65-74.9 $\mathrm{mm} \mathrm{Hg}$ and $75-90 \mathrm{~mm} \mathrm{Hg}$, respectively. The SAPS III score in the low group was 67.8 and 61.6 in the high group. According to The National Heart, Lung and Blood Institute ARDS Network trials, the 60-day mortality rate has decreased dramatically over the past two decades. In 2004-2005, it was reported to be $26 \%^{30}$, and in a more recent ARDS Network clinical trial, a 60 -day mortality rate of $22 \%$ was reported ${ }^{31-33}$.

In conclusion, 60-day mortality is not affected by first 24 hours MAP of 65-74.9 $\mathrm{mm} \mathrm{Hg}$, as compared with 75 to 90 $\mathrm{mm} \mathrm{Hg}$ for patients with AHRF under mechanical ventilation.

\section{Conflicts of Interest}

No potential conflict of interest relevant to this article was reported.

\section{Acknowledgements}

We thanks to all of the investigators conducting "Validation of Simplified Acute Physiology Score 3 in Korean ICUs" (VSKI) study.

\section{References}

1. ARDS Definition Task Force, Ranieri VM, Rubenfeld GD, Thompson BT, Ferguson ND, Caldwell E, et al. Acute respiratory distress syndrome: the Berlin Definition. JAMA 2012;307:2526-33.

2. Vincent JL, Akca S, De Mendonca A, Haji-Michael P, Sprung C, Moreno R, et al. The epidemiology of acute respiratory failure in critically ill patients $\left.{ }^{*}\right)$. Chest 2002;121:1602-9.

3. Vasilyev S, Schaap RN, Mortensen JD. Hospital survival rates of patients with acute respiratory failure in modern respiratory intensive care units: an international, multicenter, prospective survey. Chest 1995;107:1083-8.

4. Lewandowski K, Metz J, Deutschmann C, Preiss H, Kuhlen $\mathrm{R}$, Artigas A, et al. Incidence, severity, and mortality of acute respiratory failure in Berlin, Germany. Am J Respir Crit Care Med 1995;151:1121-5.

5. Antonelli M, Levy M, Andrews PJ, Chastre J, Hudson LD, Manthous C, et al. Hemodynamic monitoring in shock and implications for management. International Consensus Conference, Paris, France, 27-28 April 2006. Intensive Care Med 2007;33:575-90.

6. Dunser MW, Ruokonen E, Pettila V, Ulmer H, Torgersen C, Schmittinger CA, et al. Association of arterial blood pressure and vasopressor load with septic shock mortality: a post hoc analysis of a multicenter trial. Crit Care 2009;13:R181.

7. Sakr Y, Dubois MJ, De Backer D, Creteur J, Vincent JL. Persistent microcirculatory alterations are associated with organ failure and death in patients with septic shock. Crit Care Med 2004;32:1825-31.

8. LeDoux D, Astiz ME, Carpati CM, Rackow EC. Effects of perfusion pressure on tissue perfusion in septic shock. Crit Care Med 2000;28:2729-32.

9. Bourgoin A, Leone M, Delmas A, Garnier F, Albanese J, Martin C. Increasing mean arterial pressure in patients with septic shock: effects on oxygen variables and renal function. Crit Care Med 2005;33:780-6.

10. West JB. Invited review: pulmonary capillary stress failure. J Appl Physiol (1985) 2000;89:2483-9.

11. Dreyfuss D, Saumon G. Ventilator-induced lung injury: lessons from experimental studies. Am J Respir Crit Care Med 1998;157:294-323.

12. Esteban A, Anzueto A, Frutos F, Alia I, Brochard L, Stewart TE, et al. Characteristics and outcomes in adult patients receiving mechanical ventilation: a 28-day international study. JAMA 2002;287:345-55. 
13. Parker JC, Hernandez LA, Peevy KJ. Mechanisms of ventilator-induced lung injury. Crit Care Med 1993;21:131-43.

14. Levy MM, Artigas A, Phillips GS, Rhodes A, Beale R, Osborn T, et al. Outcomes of the Surviving Sepsis Campaign in intensive care units in the USA and Europe: a prospective cohort study. Lancet Infect Dis 2012;12:919-24.

15. Lim SY, Koh SO, Jeon K, Na S, Lim CM, Choi WI, et al. Validation of SAPS3 admission score and its customization for use in Korean intensive care unit patients: a prospective multicentre study. Respirology 2013;18:989-95.

16. Bernard GR. Quantification of organ dysfunction: seeking standardization. Crit Care Med 1998;26:1767-8.

17. National Heart, Lung, and Blood Institute Acute Respiratory Distress Syndrome (ARDS) Clinical Trials Network, Wheeler AP, Bernard GR, Thompson BT, Schoenfeld D, Wiedemann HP, et al. Pulmonary-artery versus central venous catheter to guide treatment of acute lung injury. N Engl J Med 2006;354:2213-24.

18. Brower RG, Lanken PN, MacIntyre N, Matthay MA, Morris A, Ancukiewicz M, et al. Higher versus lower positive endexpiratory pressures in patients with the acute respiratory distress syndrome. N Engl J Med 2004;351:327-36.

19. Dellinger RP, Levy MM, Rhodes A, Annane D, Gerlach H, Opal SM, et al. Surviving sepsis campaign: international guidelines for management of severe sepsis and septic shock: 2012. Crit Care Med 2013;41:580-637.

20. Asfar P, Meziani F, Hamel JF, Grelon F, Megarbane B, Anguel N, et al. High versus low blood-pressure target in patients with septic shock. N Engl J Med 2014;370:1583-93.

21. Meade MO, Cook DJ, Guyatt GH, Slutsky AS, Arabi YM, Cooper DJ, et al. Ventilation strategy using low tidal volumes, recruitment maneuvers, and high positive end-expiratory pressure for acute lung injury and acute respiratory distress syndrome: a randomized controlled trial. JAMA 2008;299:63745.

22. Annane D, Vignon P, Renault A, Bollaert PE, Charpentier C, Martin C, et al. Norepinephrine plus dobutamine versus epinephrine alone for management of septic shock: a ran- domised trial. Lancet 2007;370:676-84.

23. De Backer D, Biston P, Devriendt J, Madl C, Chochrad D, Aldecoa $\mathrm{C}$, et al. Comparison of dopamine and norepinephrine in the treatment of shock. N Engl J Med 2010;362:779-89.

24. Myburgh JA, Higgins A, Jovanovska A, Lipman J, Ramakrishnan N, Santamaria J, et al. A comparison of epinephrine and norepinephrine in critically ill patients. Intensive Care Med 2008;34:2226-34.

25. Rivers E, Nguyen B, Havstad S, Ressler J, Muzzin A, Knoblich $\mathrm{B}$, et al. Early goal-directed therapy in the treatment of severe sepsis and septic shock. N Engl J Med 2001;345:1368-77.

26. Russell JA, Walley KR, Singer J, Gordon AC, Hebert PC, Cooper DJ, et al. Vasopressin versus norepinephrine infusion in patients with septic shock. N Engl J Med 2008;358:877-87.

27. Martin C, Saux P, Eon B, Aknin P, Gouin F. Septic shock: a goaldirected therapy using volume loading, dobutamine and/or norepinephrine. Acta Anaesthesiol Scand 1990;34:413-7.

28. Dubin A, Pozo MO, Casabella CA, Palizas F Jr, Murias G, Moseinco MC, et al. Increasing arterial blood pressure with norepinephrine does not improve microcirculatory blood flow: a prospective study. Crit Care 2009;13:R92.

29. Mercat A, Richard JC, Vielle B, Jaber S, Osman D, Diehl JL, et al. Positive end-expiratory pressure setting in adults with acute lung injury and acute respiratory distress syndrome: a randomized controlled trial. JAMA 2008;299:646-55.

30. Erickson SE, Martin GS, Davis JL, Matthay MA, Eisner MD; NIH NHLBI ARDS Network. Recent trends in acute lung injury mortality: 1996-2005. Crit Care Med 2009;37:1574-9.

31. National Heart, Lung, and Blood Institute Acute Respiratory Distress Syndrome (ARDS) Clinical Trials Network, Matthay MA, Brower RG, Carson S, Douglas IS, Eisner M, et al. Randomized, placebo-controlled clinical trial of an aerosolized beta(2)-agonist for treatment of acute lung injury. Am J Respir Crit Care Med 2011;184:561-8.

32. Rice TW, Wheeler AP, Thompson BT, deBoisblanc BP, Steingrub J, Rock P, et al. Enteral omega-3 fatty acid, gammalinolenic acid, and antioxidant supplementation in acute lung injury. JAMA 2011;306:1574-81. 